Contents list available at IJRED website

Int. Journal of Renewable Energy Development (IJRED)

Journal homepage: http://ejournal.undip.ac.id/index.php/ijred

\title{
Premixed Combustion of Kapok (ceiba pentandra) seed oil on Perforated Burner
}

\author{
I.K.G. Wirawana, ${ }^{\text {, }}$, I.N.G. Wardanab, Rudy Soenoko ${ }^{\mathrm{b}}$, and Slamet Wahyudib \\ ${ }^{a}$ Mechanical Engineering Department, Udayana University, Bali, INDONESIA \\ ${ }^{b}$ Mechanical Engineering Department, Brawijaya University, East Java, INDONESIA
}

\begin{abstract}
Availability of fossil fuels in the world decrease gradually due to excessive fuel exploitation. This situations push researcher to look for alternative fuels as a source of renewable energy, one of them is kapok (ceiba pentandra) seed oil. The aim this study was to know the behavior of laminar burning velocity, secondary Bunsen flame with open tip, cellular and triple flame. Premixed combustion of kapok seed oil was studied experimentally on perforated burner with equivalence ratio $(\varphi)$ varied from 0.30 until 1.07. The results showed that combustion of glycerol requires a large amount of air so that laminar burning velocity ( $\left.\mathrm{S}_{\mathrm{L}}\right)$ is the highest at very lean mixture $(\varphi=0.36)$ in the form of individual Bunsen flame on each of the perforated plate hole. Perforated and secondary Bunsen flame both reached maximum $S_{\mathrm{L}}$ similar with that of ethanol and higher than that of hexadecane. Slight increase of $\varphi$ decreases drastically $S_{\mathrm{L}}$ of perforated and secondary Bunsen flame. When the mixture was enriched, secondary Bunsen and perforated flame disappears, and then the flame becomes Bunsen flame with open tip and triple flame $(\varphi=0.62$ to 1.07). Flame was getting stable until the mixture above the stoichiometry. Being isolated from ambient air, the $S_{\mathrm{L}}$ of perforated flame, as well as secondary Bunsen flame, becomes equal with non-isolated flame. This shows the decreasing trend of laminar burning velocity while $\varphi$ is increasing. When the mixture was enriched island ( $\varphi=0.44$ to 0.48$)$ and petal $(\varphi=0.53$ to 0.62$)$ cellular flame take place. Flame becomes more unstable when the mixture was changed toward stoichiometry.
\end{abstract}

Keywords: cellular flame, glycerol, kapok (ceiba pentandra) seed oil, perforated flame, secondary Bunsen flame with open tip, triple flame

Article History: Received Dec 22, 2013; Received in revised form March 12, 2014; Accepted May 11, 2014; Available online

How to Cite This Article: Wirawan, I.K.G., Wardana, I.N.G., Soenoko, R. \& Wahyudi, S. (2014) Premixed Combustion of Kapok (ceiba pentandra) seed oil on Perforated Burner. Int. Journal of Renewable Energy Development, 3(2), 91-97.

http://dx.doi.org/10.14710/ijred.3.2.91-97

\section{Introduction}

Availability of fossil fuels in the world decrease gradually due to excessive fuel exploitation. It occurs because of increasing need for conventional energy, in line with population growth at all of their activities. This situations push researcher to look for alternative fuels as a source of renewable energy, one of them is kapok (ceiba pentandra) seed oil.

Kapok is a tropical tree belongs to order malvales and family Malvaceae. The word kapok is used to refer fiber and seeds. Kapok fiber has the characteristics of a large lumen and the hydrophobic-oleophilic so suitable for use as (i) an absorbent to remove methylene blue from aqueous solution (Shim et al. 2013), (ii) absorption of the oil and separator filter of oil with water (Lim et al. 2007; Abdullah et al. 2010; Wang et al. 2012), (iii) removal of hazardous material because it has a uniform morphology (Hwang et al. 2013). Waste of kapok seed husks could be used as activated carbon to remove copper, cadmium (Rao et al. 2006) and lead, zinc (Rao et al. 2008) in aqueous solution.

Kapok seed oil (KSO) is one of the non-edible biodiesel feedstock that needs to be developed in

\footnotetext{
* Corresponding author:

Email: wirawan_ikg@yahoo.com
} 
Indonesia. KSO biodiesel when used directly would not meet the requirements of Standard Biodiesel Indonesia, because it contains cyclopropenoid group. Cyclopropenoid is a reactive group that is easy to polymerize, making biodiesel viscous and thus could clog of fuel injection nozzle for diesel engine (Hudaya et al. 2013). Trans-esterification process of KSO produces ceiba pentandra methyl ester (CPME) which is used to improve the properties of biodiesel such as viscosity, density, flash point, heating value and oxidation stability so that meet of biodiesel standard ASTM D6751 is recommended. Oxidation stability could be improved by means of biodiesel blended with petrodiesel that meet the standard EN 14214 (Silitonga et al. 2013; Ong et al. 2013). Biodiesel of CPME qualified SNI 0471822006 standards are also produced from the transesterification with using naturally potassium hydroxide catalyst (Handy et al. 2013). Biodiesel optimal results were obtained by two-step acid-based transesterification. Biodiesel conversion of $99.5 \%$ obtained in optimum conditions of $1.0 \mathrm{wt}$. $\% \mathrm{KOH}$ (catalyst concentration) and ratio molar of oil to methanol 6:01 (volume ratio) at a temperature of $65^{\circ} \mathrm{C}$ for reaction time of 45 minutes. The properties of fuel in accordance with the limits specified ASTM D6751 standards (Sivakumar et al. 2013). KSO biodiesel production could also be done through supercritical methanol transesterification process. The optimum reaction conditions for supercritical methanol trans-esterification of KSO to produce biodiesel is as follows: the molar ratio of oil to methanol is $30: 1$, temperature is $322{ }^{\circ} \mathrm{C}$, pressure is 16.7 $\mathrm{MPa}$, and a reaction time is 476 seconds, with the results of fatty acid methyl ester (FAME) is 95.5\% (Ong et al. 2013). So far, more KSO was used as a nonpremixed combustion. Engine running with kapok methyl ester (KME) was investigated experimentally. The thermal efficiency of the engine at B25 mixture is higher than conventional diesel by $4 \%$ and the resulting exhaust emissions such as $\mathrm{HC}, \mathrm{CO}, \mathrm{NO}$ and smoke is similar (Vedharaj et al. 2013).

The research of vegetable oil combustion is commonly focused on non-premixed combustion. The results are applicable only for diesel engine. In order to extend the vegetable oil application, such as for spark ignition engine, study on premixed combustion of vegetable oil needs to be undertaken. Premixed combustion research using vegetable oil is still limited, especially in KSO. Thus, the premixed combustion research using KSO becomes important. However, KSO needed to be evaporated before it could be used in premixed combustion.

KSO is very interesting to be studied because of the hygroscopic glycerol and fatty acids that have different properties. Both of these will affect flame behavior in premixed combustion such as laminar burning velocity, Bunsen flame with open tip, cellular and triple flame.

Researches on premixed combustion were mostly done using conventional fuels. Laminar burning velocity was measured with variation at equivalence ratio, initial pressure, preheating temperature by using a natural gas-air mixture (Liao et al. 2004). Cylindrical burner was used on the experiment of Bunsen flame with open tip when hydrogen-methane-nitrogen mixture at varying concentrations ratio was diluted using inert gas (Ishizuka et al. 1982). Lewis numbers less than one was caused by thermal diffusion and a hydrodynamic instability so that cellular flame occurred (Kadowaki 2005). Co-flow type was used to see triple flame with different equivalence ratio of the reactants flow on inner and outer burner (Sahu et al. 2009).

This paper discusses the behavior of laminar burning velocity, secondary Bunsen flame with open tip, cellular and triple flame using $\mathrm{KSO}$, which provide wider theoretically benefits in the premixed combustion of vegetable oils.

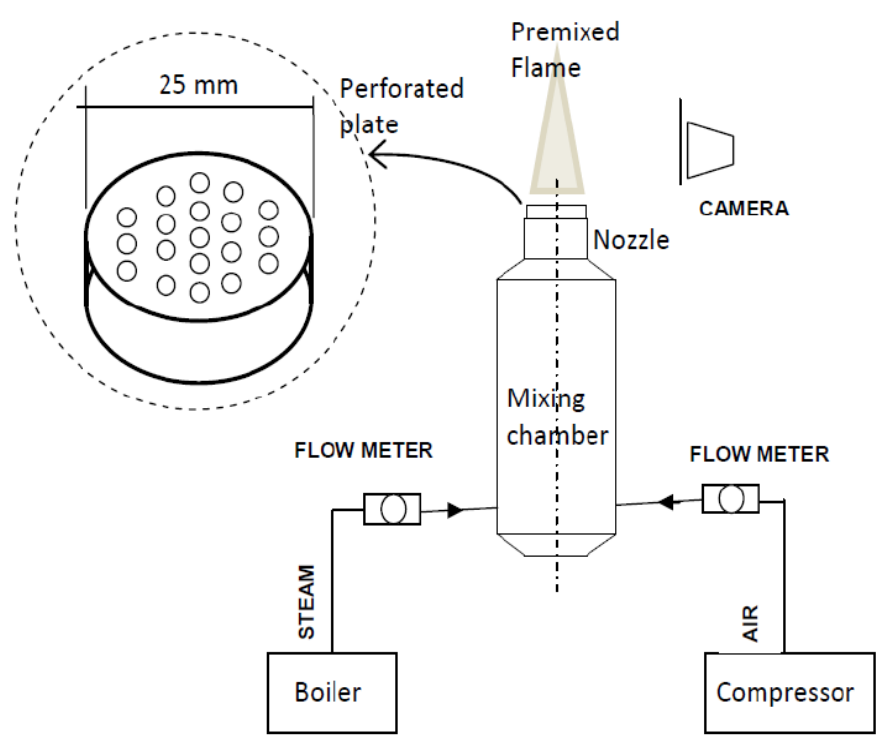

Fig. 1 Experimental apparatus 


\section{Experiments}

KSO premixed combustion was studied experimentally using experimental apparatus shown schematically in Fig.1. Boiler were used for evaporating $\mathrm{KSO}$ with constant steam temperature at $160^{\circ} \mathrm{C}$. The oil from evaporating process was mixed with air from compressor in mixing chamber at equivalent ratio $(\varphi)$ varied from 0.30 to 1.07 . The reactant mixture then flows into the nozzle before ignited in order to form premixed flame at perforated plate installed above the nozzle.

The function of perforated plate was to utilize thermal contact resistant in preserving temperature distribution which is more uniform in entire plate surface and to stabilize the uniformity flow for KSO with air during combustion. Perforated plate was designed from steel with 19 holes. The each hole was set with 2.5 $\mathrm{mm}$ diameter and $3.75 \mathrm{~mm}$ distance between them.

The flame image was captured by camera in two experimental conditions: (1) premixed flame of KSO in contact with surrounding air (2) premixed flame of coconut oil shielded from surrounding air.

The KSO used in this study consists of $85 \%$ fatty acid and 15\% glycerol. It was obtained in Malang East Java. The component of fatty acids in KSO is listed in Table 1 . These fatty acids were tested in laboratory research and testing integrated in Gajah Mada University Yogyakarta. Most of the components are unsaturated long chain fatty acids. More than 79\% of those are mono and polyunsaturated long chain with spontaneous combustion characteristics. The total molecular weight of fatty acid described with equation 1. The reaction of KSO with the oxidizer was estimated by molar analysis described with equation 2 and equation 3 as follows:

$$
\mathrm{MW}_{\mathrm{t}}=\sum_{1}^{\mathrm{n}}(\mathrm{MWxC})
$$

where:

$\mathrm{MW}_{\mathrm{t}} \quad=$ Total molecular weight

$\mathrm{MW} \quad=$ molecular weight of fatty acid

$\mathrm{C}=$ content of fatty acid

$\mathrm{N} \quad$ = number of fatty acid

$0,00853 \mathrm{C}_{4} \mathrm{H}_{6} \mathrm{O}_{2}+0,00028 \mathrm{C}_{6} \mathrm{H}_{12} \mathrm{O}_{2}+0,00009 \mathrm{C}_{8} \mathrm{H}_{16} \mathrm{O}_{2}+$ $0,00072 \mathrm{C}_{10} \mathrm{H}_{20} \mathrm{O}_{2}+0,00071 \mathrm{C}_{12} \mathrm{H}_{24} \mathrm{O}_{2}+0,01222$ $\mathrm{C}_{14} \mathrm{H}_{28} \mathrm{O}_{2}+0,02462 \mathrm{C}_{16} \mathrm{H}_{32} \mathrm{O}_{2}+0,00387 \mathrm{C}_{16} \mathrm{H}_{30} \mathrm{O}_{2}+$ $0,0016 \mathrm{C}_{17} \mathrm{H}_{34} \mathrm{O}_{2}+0,20153 \mathrm{C}_{18} \mathrm{H}_{34} \mathrm{O}_{2}+0,53786 \mathrm{C}_{18} \mathrm{H}_{32} \mathrm{O}_{2}$ $+0,130337 \mathrm{C}_{18} \mathrm{H}_{30} \mathrm{O}_{2}+0,00026 \mathrm{C}_{20} \mathrm{H}_{40} \mathrm{O}_{2}+0,00995$ $\mathrm{C}_{22} \mathrm{H}_{44} \mathrm{O}_{2}+0,04229 \mathrm{C}_{20} \mathrm{H}_{32} \mathrm{O}_{2}+0,00672 \mathrm{C}_{24} \mathrm{H}_{48} \mathrm{O}_{2}+$ $0,01837 \mathrm{C}_{24} \mathrm{H}_{46} \mathrm{O}_{2}+33,20\left(\mathrm{O}_{2}+3.76 \mathrm{~N}_{2}\right) \rightarrow 18,03 \mathrm{CO}_{2}+$ $32,33 \mathrm{H}_{2} \mathrm{O}+124,83 \mathrm{~N}_{2}$

$$
\mathrm{C}_{3} \mathrm{H}_{5}(\mathrm{OH})_{3}+3.5\left(\mathrm{O}_{2}+3.76 \mathrm{~N}_{2}\right) \rightarrow 3 \mathrm{CO}_{2}+4 \mathrm{H}_{2} \mathrm{O}
$$

The equation 2 is the combustion reaction of fatty acids molecule from present data in Table 1 and equation 3 is that of glycerol. The stoichiometric air fuel ratio (AFR stoic) of KSO obtained from equation 1, 2 and 3 was 14.58 gram air/ gram fuel. In KSO without glycerol the AFR stoic was 16.23 gram air/ gram fuel. The $\varphi$ was calculated as the ratio of stoichiometric air fuel ratio and actual air fuel ratio.

Table 1

\begin{tabular}{|c|c|c|c|}
\hline \multirow[b]{2}{*}{ Fatty acid } & \multicolumn{3}{|c|}{$\%(w / w)$} \\
\hline & $\begin{array}{c}\text { Present } \\
\text { data }\end{array}$ & $\begin{array}{l}\text { Sivakumar et al. } \\
2012\end{array}$ & $\begin{array}{l}\text { Silitonga et } \\
\text { al. } 2013\end{array}$ \\
\hline Butiric $(\mathrm{C} 4: 0)$ & 0,853 & - & - \\
\hline Caproic (C6:0) & 0,028 & - & - \\
\hline Caprylic (C8:0) & 0,009 & - & - \\
\hline Capric (C10:0) & 0,072 & - & - \\
\hline Lauric (C12:0) & 0,071 & - & 0,1 \\
\hline Myristic (14:0) & 1,222 & 0,11 & 0,1 \\
\hline Palmitic (16:0) & 2,462 & 23,20 & 19,2 \\
\hline Palmitolic (16:1) & 0,387 & - & 0,3 \\
\hline Heptadecanoic (C17:0) & 0,16 & - & - \\
\hline Stearic (18:0) & - & 5,68 & 2,6 \\
\hline Oleic (18:1) & 20,153 & 29.69 & 17,4 \\
\hline Linoleic (18:2) & 53,786 & 35,11 & 39.7 \\
\hline Linolenic (18:3) & 13,0337 & - & 1,5 \\
\hline Arachidic $(20: 0)$ & 0,026 & 1,89 & 0.6 \\
\hline Arachidonic (20:4) & 0,995 & - & - \\
\hline Behenic (22:0) & 4,229 & 0,25 & - \\
\hline Lignoceric (C24:0) & 0,672 & 1,51 & - \\
\hline Nervonic $(24: 1)$ & 1,837 & - & - \\
\hline Malvalic (18:CE) & - & - & 18.5 \\
\hline
\end{tabular}

Kapok seed oil (ceiba pentandra) composition from many references

\section{Result and Discussion}

KSO composed of fatty acids and glycerol. More than $79 \%$ of fatty acids components are unsaturated fatty acids and the other $21 \%$ are saturated straightchain long hydrocarbons with ranges from 4 to 24 carbons with carbocyclic or $\mathrm{COOH}$ end. Fatty acids and glycerol could affect reaction of the combustion process and the flame characteristics.

KSO flame on the perforated burner at various equivalence ratios is shown in Fig. 2 to 4 . Figure 2 shows that Glycerol intensively burned from $\varphi=0.32$ to 1.07 (Wardana 2010). There were more glycerol burned in lean mixture $(\varphi=0.44)$ which made $\varphi$ away from stoichiometry. Fig. 3a shows pelrabrated flame with secondary Bunsen flame and Fig. 3b shows triple flame at lean mixture.
(3) 


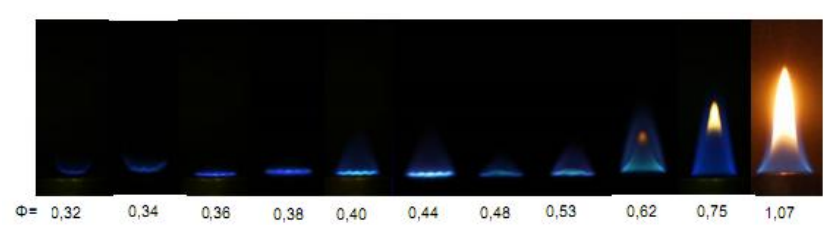

Fig. 2 Flame structure of KSO oil with glycerol

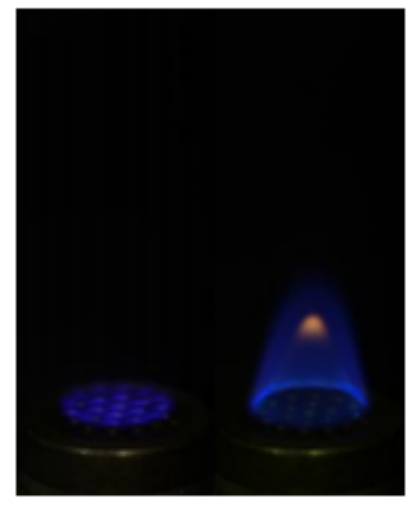

(a)

(b)

Fig. 3 view of KSO (a) perforated flame at $\varphi=0.44$, triple flame at $\varphi=0.62$

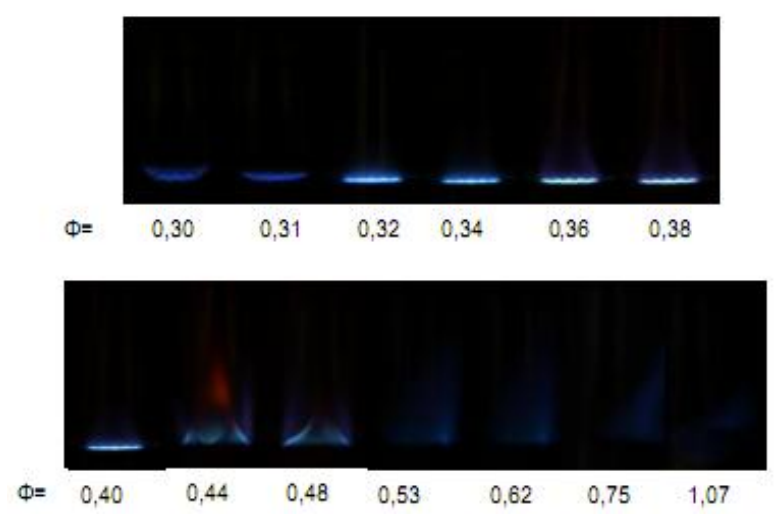

Fig. 4 Flame shapes of KSO with glycerol isolated from ambient air

Fig. 4 show the flame isolated from the surrounding ambient air at $\varphi=0.30$ to 1.07 . At $\varphi=0.30$ to 0.31 of perforated flame lifts off. When $\varphi$ increases the perforated flame occurs at $\varphi=0.32$ to 0.40 followed by secondary Bunsen flame. At $\varphi=0.40$ to 1.07 perforated and secondary Bunsen flame becomes unstable in the form of cellular and extinction flame. This phenomenon shows that KSO requires a large amount of air or flame formed in the lean mixture so that flame stability is influenced by the air supply.

\subsection{Laminar Flame Velocity}

Reactant velocity (v) is described in equation (4).

$$
v=\frac{Q_{\text {fuel }}+Q_{\text {air }}}{A_{b}}
$$

where:

$\mathrm{Q}_{\text {fuel }} \quad=$ volume flow rate of fuel

$\mathrm{Q}_{\text {air }} \quad=$ volume flow rate of air

$\mathrm{A}_{\mathrm{b}} \quad=$ burner cross section area.

Laminar flame speed $\left(\mathrm{S}_{\mathrm{L}}\right)$ could be estimated by using equation (5) as:

$S L=v \sin \alpha$

where: $\alpha=$ half angel of the Bunsen flame cone tip.

Fig. 5 shows the laminar burning velocity, $\mathrm{S}_{\mathrm{L}}$ estimated from Fig.2 using the equation 4. It is seen that the maximum $S_{\mathrm{L}}$ of perforated flame occurred at a very lean mixture is between that of hexadecane (Chaos et al. 2005) and ethanol flame (Broustail et al. 2011) at stoichiometric. Perforated flame lifts off at $\varphi=0.32$ to 0.34 . The increase of $\varphi$ from 0.36 to 0.44 decreases perforated flame burning velocity. Secondary Bunsen flame is formed from $\varphi=0.40$ to 0.53 with declining burning velocity. When $\varphi$ increased to $\varphi=1.07$, Bunsen flame with open tip were formed with declining burning velocity. This shows that flammability limits of KSO is much wider than conventional fossil fuels at lean mixture.

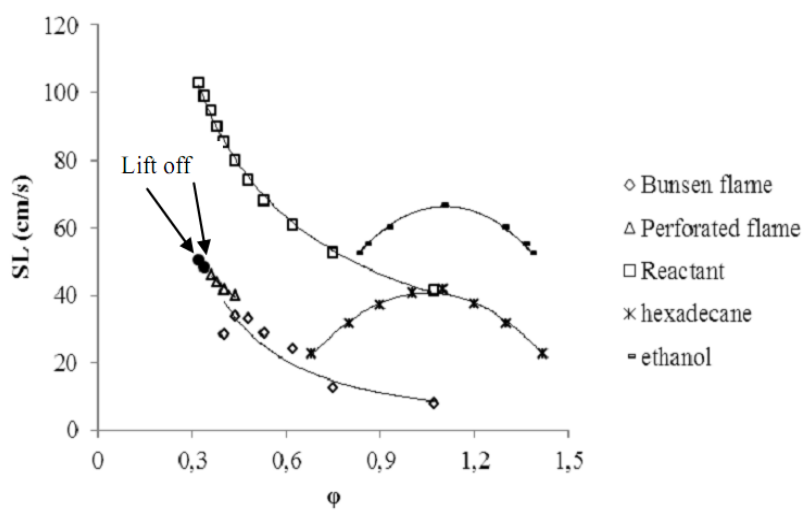

Fig. 5 Laminar burning velocity of KSO versus equivalence ratio

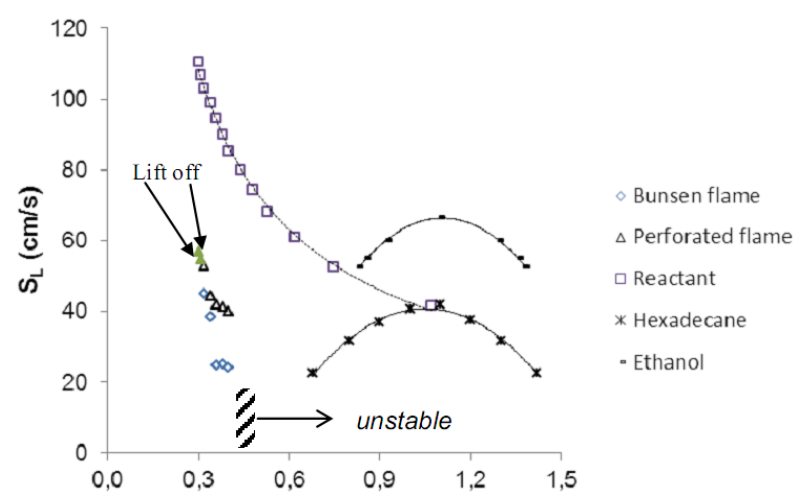

Fig. 6 Laminar burning velocity of KSO versus equivalence ratio 
Figure 6 presents $S_{\mathrm{L}}$ of KSO estimated from Fig. 4 using equation 5 when the flame is isolated from the ambient air. It could be seen that SL of perforated flame at very lean mixture almost equal to that of ethanol flame (Broustail et al. 2011) and higher than that of hexadecane flame (Chaos et al. 2005) at stoichiometry. Increasing $\varphi$ from 0.32 to 0.40 causes a burning speed of both perforated and secondary Bunsen flame decreases. Perforated flame extinct above $\varphi=0.40$ and cellular flame disappears above $\varphi=0.40$ from where to the flame becomes unstable (Fig. 4). Once again, this indicates that glycerol requires a large amount of air to burn so the flame is stable in very lean mixtures.

\subsection{Bunsen Flame with Open Tip}

Opening tip on the Bunsen flame occurs when using a large amount of inert gas on diluted mixture, while the fatty acid and glycerol mixtures showed the maximum flame temperature on reaction zone toward dilation of flame tip. Amount of fuel that does not burn on the arm of a hydrogen molecule of fatty acid and glycerol were found exit through the open space. These event causes fuel leaks and pollutant emissions on the diffusion flames burning on the fuel mixture that resulted Bunsen flame with open tip.

KSO with a mixture of very lean, the amount of air on the mixture is enough to complete combustion. High burning speed of flame occurred on every hole at perforated nozzle. The equivalence ratio $\varphi$ increases, fraction of fuel on the mixture also increases so that the more energy absorption to ignite the mixture. As a result, the laminar burning velocity of long-chain saturated fatty acids and glycerol are very low, it produces of secondary Bunsen flame at perforated flame downstream. Laminar burning velocity is much lower than the reactant velocity, the Bunsen flame tends to stretch so that open tip. Equivalence ratio $\varphi$ enriched a long chain saturated fatty acids and glycerol becomes difficult to burn, eventually escaped towards product zone to produce a yellow sooty diffusion at flame tip. It is clearly seen from the Fig. 7 that the formation of the open tip of KSO flame at $\varphi=1.07$.

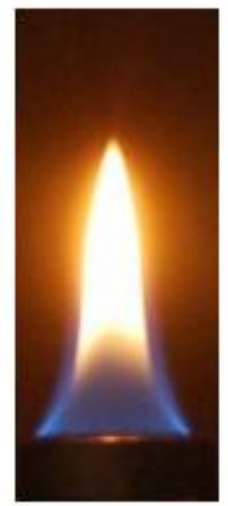

Fig. 7 Bunsen flame with open tip of KSO
Mechanism of Bunsen flame with open tip formed by both escaped unburnt fuel and pollutants is based on the concept of Damkohler number because laminar burning velocity is much lower than the reactant velocity (Ishizuka \& Sakai 1986).

\subsection{Cellular Flame}

Fig. 8 shows the detailed structure of cellular flame of KSO when the ambient air is not contact with flame. Cellular flame occurs because the heat is not enough to burn the fuel that is, Lewis number (Le) is smaller than 1. Fig. 8a shows cellular flames at lean mixture $(\varphi=$ $0.44)$. In this case, fraction of air in the mixture is not enough to burn glycerol in KSO. Glycerol escapes to product zone becoming diffusion flame. Radiant heat of glycerol diffusion flame provides heat energy for burning of medium chain fatty acids but it is not enough to burn the long one. Therefore, cellular flame is generated on the perforated plate. This phenomenon is similar with that reported in Kadowaki et al. (2011).

At higher $\varphi$, the air is not enough for maintaining diffusion flame and the radiant heat disappears. Therefore, the long and medium chain fatty acids produce petals cellular flame in the Bunsen flame as shown in Fig. 8b. This result is similar with that discussed in Wirawan et al. (2013).

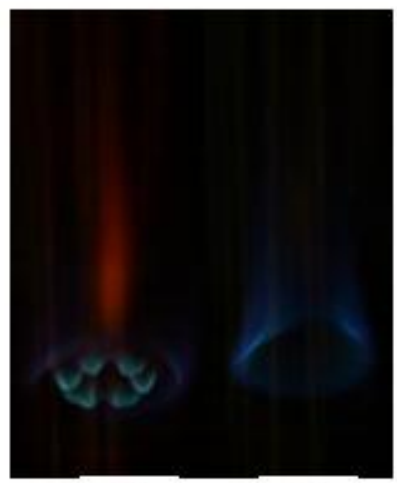

(a)

(b)

Fig. 8 Cellular flame of KSO Islands cellular at $\varphi=0.44$, (b) petal cellular at $\varphi=0.62$

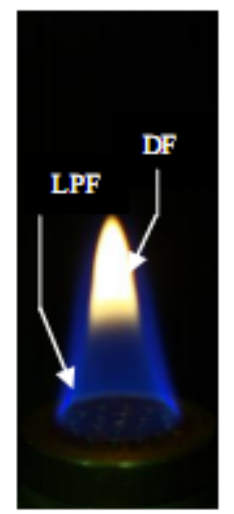

Fig. 9 Triple flame shape of $\operatorname{KSO}$ at $\varphi=0.75$ 


\subsection{Triple Flame}

In Fig. 2, triple flame of KSO is formed at $\varphi=0.62$ to 1.07 where the flame is left in contact with ambient air. Fig. 9 shows the detailed structure of the triple flame at $\varphi=0.75$. Flame composed by rich premixed flame (RPF) in the upstream region, diffusion flame (DF) in the middle, and the lean premixed flame (LPF) in the downstream region. Flame structure is formed from a premixed combustion process of KSO caused by instability of thermal diffusive. RPF is due to heat flux propagation increasing and unburned gas temperature in the upstream so that flow leads convergent and flame front becomes convex.

Glycerol in KSO is difficult to be burned in the reaction zone because the air is not enough and escapes to product zone becoming diffusion flame. Diffusion flame both could not expand the reaction zone due to fuel lack and could not move in the direction of reaction zone due to air lack. Inability of diffusion flame propagation causes free convection in the downstream of pumping cool air toward the reaction zone to meet and react with RPF to produce LPF in the downstream region. Triple flame formed by free convection of hot gas recirculation region at lean premixed flame or unstable flame occurs when the hot gas moving downstream as found by Jime'nez \& Cuenot (2007).

\section{Conclusion}

Kapok seed oil premixed combustion has been studied experimentally on perforated burner with equivalent ratio varied from very lean until rich mixture. The results showed that at very lean mixture Bunsen flame is performed on every hole of perforated plate. The velocity of both perforated and secondary Bunsen flame decreased when equivalent ratio increased. Both open tip Bunsen and triple flame were formed in higher equivalent ratio.

When the flame was isolated from the ambient air, the slight increase of equivalence ratio makes laminar burning velocity decreases drastically. The open tip Bunsen and triple flame disappear while perforated and secondary Bunsen flame is still occurs. Cellular flame was formed with higher equivalent ratio. This phenomenon shows that premixed combustion of kapok seed oil requires a large amount of air.

\section{Acknowledgements}

This research is supported by The General Directorate of Higher Education (DIKTI) with contract number 692/H10.14/AK/2010 via Prostgraduate Program, Brawijaya University East Java, Indonesia.

\section{References}

Abdullah, M.A., Rahmah, A.U. \& Man, Z. (2010) Physicochemical and sorption characteristics of Malaysian Ceiba pentandra (L.) Gaertn. as a natural oil sorbent. Journal of Hazardous Materials, 177, 683691.

Broustail, G., Seers, P., Halter, F., Moréac, G. \& Mounaim, R.C. (2011) Experimental determination of laminar burning velocity for butanol and ethanol iso-octane blends. Fuel, 90, 1-6.

Chaos, M., Kazakov, A., Dryer, F.L., Zhao, Z. \& Zeppieri, S.P. (2005) High temperature compact mechanism development for large alkanes: n-hexadecane. 6th International Conference on Chemical Kinetics.

Chung, J.T., Hwang, K.J., Shim, W.G., Choi, C.K.D.Y., Lee, J.W. \& Park, J.Y. (2013) Synthesis and characterization of activated hollow carbon fibers from Ceiba pentandra (L.) Gaertn. (kapok). Materials Letters, 93, 401-403.

Hudaya, T., Liana, \& Soerawidjaja, T.H. (2013) A study on low temperature and pressure hydrogenation of cyclopropenoidgroup containing non-edible oil for biodiesel Feedstock. Energy Procedia, 32, 209-215.

Hwang, K.J., Kang, D., Lee, S., Kim, C.H.H.N., Jin, S., Lee, I.H., Park, J.Y. \& Kim, C. (2014) Synthesis and characterization of hollow $\mathrm{TiO}_{2}$ fibers using Ceiba pentandra (L.) Gaertn. (kapok) as a natural template. Materials Letters, 115, 265-267.

Ishizuka, S. \& Sakai, Y. (1986) Structure and tip-opening of laminar diffusion flames. Twenty fist Symposium (International) on Combustion / The Combustion Institute, 1821-1828.

Jime'nez, C. \& Cuenot, B. (2007) DNS study of stabilization of turbulent triple flames by hot gases, Proceedings of the Combustion Institute, 31, 1649-1656.

Kadowaki, S., Suzuki, H. \& Kobayashi, H. (2005) The unstable behavior of cellular flames induced by intrinsic instability. Proceedings of the Combustion Institute, 30, 169-176.

Liao, S.Y., Jiang, D.M. \& Cheng, Q. (2004) Determination of laminar burning velocities for natural gas. Fuel, 83, 1247-1250.

Lim, T.T. \& Huang, X. (2007) Evaluation of hydrophobicity/ oleophilicity of kapok and its performance in oily water filtration: Comparison of raw and solvent- treated fibers. Industrial Crops and Products, 26, 125-134.

Lim, T.T. \& Huang, X. (2007) Evaluation of kapok (Ceiba pentandra (L.) Gaertn.) as a natural hollow hydrophobic-oleophilic fibrous sorbent for oil spill cleanup. Chemosphere, 66, 955-963.

Ong, L.K., Effendi, C., Kurniawan, A., Lin, C.X., Zhao, X.S. \& Ismadji, S. (2013) Optimization of catalyst-free production of biodiesel from Ceiba pentandra (kapok) oil with high free fatty acid contents. Energy, 57, 615-623.

Ong, H.C., Silitonga, A.S., Masjuki, H.H., Mahlia, T.M.I., Chong, W.T. \& Boosroh, M.H. (2013) Production and comparative fuel properties of biodiesel from non-edible oils: Jatropha curcas, Sterculia foetida and Ceiba pentandra. Energy Conversion and Management, $73,245-255$.

Rao, M. M., Rao, G.P.C, Seshaiah, K., Choudary, N.V. \& Wang, M.C. (2008) Activated carbon from ceiba pentandra hulls, an agricultural waste, as an adsorbent in the removal of lead and zinc from aqueous solutions. Waste Management, 28, 849-858.

Rao, M. M., Ramesh, A., Rao, G.P.C. \& Seshaiah, K. (2006) Removal of copper and cadmium from the aqueous solutions by activated carbon derived from Ceiba pentandra hulls. Journal of Hazardous Materials B, 129, 123-129.

Sahu, K.B., Kundu, A., Ganguly, R. \& Datta, A. (2009) Effects of fuel type and equivalence ratios on the flickering of triple flames. Combustion and Flame, 156, 484-493.

Silitonga, A.S., Ong, H.C., Mahlia, T.M.I., Masjuki, H.H. \& Chong, W.T. (2013) Characterization and production of ceiba pentandra biodiesel and its blends. Fuel, 108, 855-858.

Sivakumar, P., Sindhanaiselvan, S., Gandhi, N.N., Devi, S.S. \& Renganathan, S. (2013) Optimization and kinetic studies on biodiesel production from underutilized Ceiba Pentandra oil, Fuel, 103, 693-698.

Tye, Y.Y., Lee, K.T., Abdullah, W.N.W. \& Leh, C.P. (2012) Potential of Ceiba pentandra (L.) Gaertn. (kapok fiber) as a resource for second generation bioethanol: Effect of various simple 
pretreatment methods on sugar production. Bioresource Technology, 116, 536-539.

Tye, Y.Y., Lee, K.T., Abdullah, W.N.W. \& Leh, C.P. (2013) Potential of Ceiba pentandra (L.) Gaertn. (kapok) fiber as a resource for second generation bioethanol: Parametric optimization and comparative study of various pretreatments prior enzymatic saccharification for sugar production. Bioresource Technology, 140, 10-14.

Vedharaj, S., Vallinayagam, R., Yang, W.M., Chou, S.K., Chua, K.J.E. \& Lee, P.S. (2013) Experimental investigation of kapok (Ceiba pentandra) oil biodiesel as an alternate fuel for diesel engine. Energy Conversion and Management, 75, 773-779.

Wang, J., Zheng, Y. \& Wang, A. (2012) Effect of kapok fiber treated with various solvents on oil absorbency. Industrial Crops and Products, 40, 178-184.

Wardana, I.N.G (2010) Combustion characteristics of jatropha oil droplet at various oil temperatures. Fuel, 89, 659-664.

Wirawan, I.K.G., Wardana, I.N.G., Soenoko, R. \& Wahyudi, S. (2013) Premixed combustion of coconut oil on perforated burner. Int. Journal of Renewable Energy Development, 2(3), 133-139. 